\title{
Impact of Serum TSH and Anti-Thyroglobulin Antibody Levels on Lymph Node Fine-Needle Aspiration Thyroglobulin Measurements in Differentiated Thyroid Cancer Patients
}

\author{
Marta Amaro da Silveira Duval André Borsatto Zanella Ana Patrícia Cristo \\ Carlo Sasso Faccin Marcia Silva Graudenz Ana Luiza Maia
}

Thyroid Unit, Endocrine Division, Hospital de Clínicas de Porto Alegre, Faculdade de Medicina, Universidade Federal do Rio Grande do Sul, Porto Alegre, Brazil

\section{Keywords}

Differentiated thyroid carcinoma - Lymph nodes .

Thyroglobulin

\begin{abstract}
Background: Thyroglobulin measurements in the washout of fine needle aspiration (FNA-Tg) are an excellent tool to detect lymph node (LN) metastases of differentiated thyroid carcinoma (DTC). Nevertheless, how to define the best cutoffs and the influence of potential confounders are still being discussed. Objective: To evaluate the accuracy of FNA-Tg measurement to detect DTC metastases and the influence of thyroid status and anti-thyroglobulin antibodies ( $\mathrm{TgAb}$ ). Methods: One hundred thirty-eight patients with DTC and suspicious cervical LN were included. Patients underwent ultrasound (US)-guided FNA for cytological examination and FNA-Tg measurements. Final diagnoses were confirmed by histological examination or clinical and US follow-up for at least 1 year. Results: Data from 119 subjects with suspicious $\mathrm{LN}$ were evaluated. The median value of FNA-Tg in patients with metastatic LN $(n=65)$ was $3,263.0 \mathrm{ng} / \mathrm{mL}(838.55-$ $12,507.5)$, while patients without LN metastasis $(n=54)$
\end{abstract}

showed levels of $0.2 \mathrm{ng} / \mathrm{mL}(0.2-0.2)$. According to the ROC curve analysis, the best cutoff value to predict metastasis was $4.41 \mathrm{ng} / \mathrm{mL}$ for FNA-Tg, with a sensitivity of $98 \%$ and specificity of $96 \%$. There were no differences in the median of FNA-Tg measurements between those on (TSH $0.16 \mathrm{mUI} /$ $\mathrm{mL}$ ) and those off levothyroxine (TSH $99.41 \mathrm{mUI} / \mathrm{mL}$ ) therapy (47.94 vs. $581.15 \mathrm{ng} / \mathrm{mL}$, respectively; $p=0.79$ ). Interestingly, the values of FNA-Tg in patients with LN metastasis $(n=65)$ did not differ between patients with positive and those with negative $\operatorname{TgAb}$ ( 88.8 vs. $3,263.0 \mathrm{ng} / \mathrm{mL}$, respectively; $p=$ 0.57). Conclusion: US-guided FNA-Tg proved to be a useful examination in the follow-up of patients with DTC, independently of TSH status and the presence of TgAb.

(C) 2017 European Thyroid Association Published by S. Karger AG, Basel

\section{Introduction}

Differentiated thyroid cancer (DTC) is the most common endocrine cancer, accounting for approximately $90 \%$ of the thyroid gland malignancies [1]. DTC prevalence has risen in the last decades, mainly due to the

\section{KARGER}

E-Mail karger@karger.com

www.karger.com/etj (c) 2017 European Thyroid Association

Published by S. Karger AG, Basel
Ana Luiza Maia, MD, PhD

Serviço de Endocrinologia do Hospital de Clínicas de Porto Alegre

Rua Ramiro Barcelos, 2350 - Prédio 12 - 4 andar/sala 401

Bairro Santa Cecília, Porto Alegre, RS 90035-903 (Brazil)

E-Mail almaia@ufrgs.br 
papillary subtype, responsible for more than $80 \%$ of the cases [2]. While there is a consensus that the increasing use of imaging examinations contributes to the rising detection of subclinical disease, there is also an increased incidence of DTC of all sizes, including larger tumors $[3,4]$.

The disease generally has a good prognosis, especially among low-risk patients. The recurrence rate in patients who had been classified as disease-free after the initial therapy was only $2.8 \%$ after a median follow-up of 4 years, and even lower $(0.6 \%)$ when considering structural disease [5]. However, recurrence of the tumor in cervical lymph nodes (LNs) occurs in up to $15 \%$ of patients after initial therapy [6]. The diagnosis of cervical LN metastases of DTC is often complex because inflammatory lymphadenopathies are extremely frequent in this region. Furthermore, metastases in cervical LNs from nonthyroidal cancers are also relatively common [7]. Sonographic features that suggest malignant LNs are increased size, loss of hilum, rounded shape, hyperechoic punctuations, cystic formation, peripheral vascularization, and microcalcifications [8]. Suspicious LNs are confirmed through fine needle aspiration (FNA) cytology guided by ultrasound (US). Nevertheless, inadequate cellularity or unsatisfying sampling precludes diagnosis in up to $20 \%$ of specimens, depending on the cytopathologist's experience and skill $[9,10]$.

Measurement of thyroglobulin in the washout of fine needle aspiration (FNA-Tg) has been used as an additional tool to detect LN disease, and is especially useful in cystic LNs, inadequate cytological evaluation, and divergent cytology and US image [11-15]. Nevertheless, there is still some debate on defining the best cutoffs according to the clinical situation, with higher cutoffs suggested in non-thyroidectomized patients [16]. Moreover, one study suggests that positive serum anti-thyroglobulin antibodies (TgAb) lowered FNA-Tg levels and influenced the diagnostic accuracy of FNA-Tg in suspicious LNs of preoperative patients $[17,18]$, while others raise the possibility that suppressed thyrotropin (TSH) resulted in false-negative FNA-Tg in malignant cases [16]. Lack of method standardization makes interpretation difficult $[19,20]$.

Here we aim to evaluate the accuracy in the detection of DTC metastases with FNA-Tg measurements seeking to assess the best cutoff point for the method, as well as to evaluate the potential confounders of FNA-Tg, such as level of serum TSH and TgAb.

\section{Materials and Methods}

\section{Patients and Study Design}

Between October 2012 and September 2016, 138 consecutive patients with DTC and suspicious cervical LNs (detected by palpation or cervical US) attending the Endocrine Division at our Institution were invited to participate in the study. The patients underwent a physical examination and blood was obtained for measurement of serum TSH, thyroglobulin (sTg), and TgAb.

Neck US and US-FNA were performed in all patients using a 10.3-MHz linear transducer. US-FNA of suspicious LNs was performed with a 21-G needle, allowing for both cytological examination and FNA-Tg. The cells were spread on a glass slide, and $1 \mathrm{~mL}$ normal saline $(0.9 \% \mathrm{NaCl})$ was aspirated through the needle with a syringe from a test tube ( $2 \mathrm{~mL}$ Eppendorf). The cytology results were classified into 3 distinct diagnostic categories: (i) inadequate or nondiagnostic: presence of blood cells without lymphocytes, plasma cells, histiocytes, and epithelial cells; (ii) negative cytology: presence of lymphocytes and occasional plasma cells without malignant epithelial cells; and (iii) positive cytology for DTC metastases: presence of epithelial cells with malignant cytological characteristics.

According to the sTg, FNA-Tg, and cytological reports and clinical judgment, patients were referred for surgery, therapeutic radioactive iodine (RAI) dose or follow-up, as decided by the attending physician. Histologic examination was considered the gold standard to determine the accuracy of FNA-Tg. For patients who did not undergo surgery, we used the negative cytological result and follow-up for at least 1 year. The following criteria were used to consider patients free of metastatic neck disease: cervical US without enlargement of LNs or presence of LNs without malignant characteristics (hyperechoic punctuations, loss of hilum, and peripheral vascularization) and undetectable stimulated sTg. The study was approved by the Ethics Committee of our Institution and all patients gave informed consent.

\section{Laboratory Measurements}

TSH levels were measured by electrochemiluminescence immunoassay (ADVIA Centaur XP; Siemens, Tarrytown, NY, USA), with a reference range of 0.4-4.2 mIU/L. sTg and FNA-Tg were measured by chemiluminescence (ECLIA), using a commercially available kit (Modular E-170 Roche). The reference range for thyroglobulin measurements was $0.2-70.0 \mathrm{ng} / \mathrm{mL}$. The TgAb were measured by chemiluminescent microparticle immunoassay (Siemens Healthcare, Diagnostics Products Ltd., Llanberis, Gwynedd, $\mathrm{UK}$ ) with a reference value $<4.11 \mathrm{IU} / \mathrm{mL}$.

\section{Statistical Analysis}

Results are expressed as frequencies, mean, standard deviation, or median (range). Clinical and laboratory data were compared using the unpaired Student $t$ test, Mann Whitney U test, or $\chi^{2}$ test, as appropriate. A two-tailed $p<0.05$ was considered statistically significant. Receiver operating characteristic (ROC) curve analysis was performed to determine the best cutoff value of FNA-Tg for the diagnosis of malignant LNs. All analyses were performed using the Statistical Package for Social Science professional software version 20.0 (SPSS, Chicago, IL, USA). 


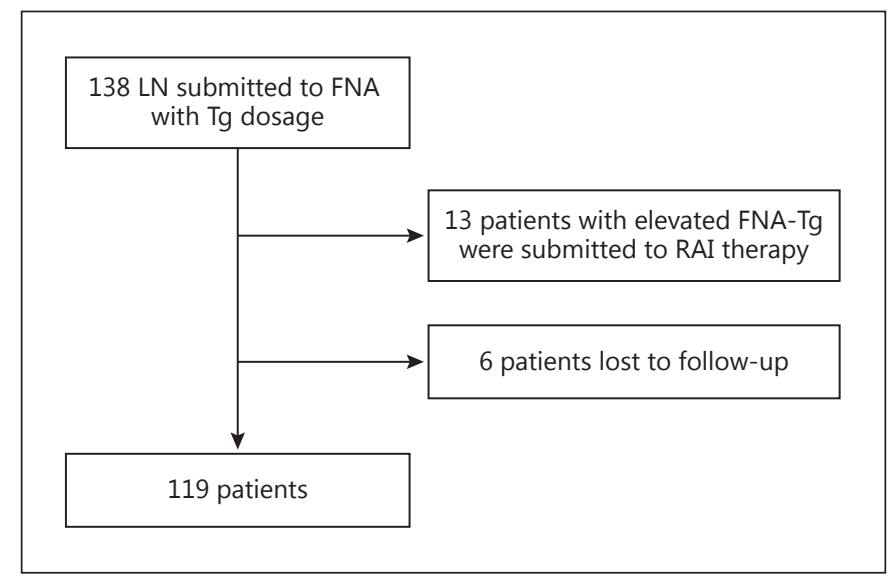

Fig. 1. Flow chart of patients who met inclusion/exclusion criteria for the study population.

\section{Results}

\section{Clinical Characteristics}

One hundred thirty-eight DTC patients who were submitted to LN FNA-Tg dosage were included in the study. After initial evaluation, 19 patients were excluded because of lack of data, loss of follow-up or RAI administration (Figure 1). One hundred and nineteen patients with suspicious LNs were included ( 89 women and 30 men) with a mean age of 45.9 years $( \pm 16.5)$. One hundred and five $(92.9 \%)$ had papillary histology. According to TNM staging for DTC, patients were distributed as follows: stage I (52.9\%), II (10.9\%), III (15.1\%), and IV (12.6\%); 10 (8.4\%) patients had unknown TNM, because of lack of information. The median size of LNs was $1.5 \mathrm{~cm}(1.1-2.1)$ and the median follow-up was 23 months (13-34) after FNA-Tg analysis. Ninety-six patients were receiving levothyroxine (LT4) suppressive therapy with a median TSH $0.16 \mathrm{mUI} / \mathrm{mL}(0.03-1.78)$, while 18 patients had hypothyroidism (levothyroxine withdrawal) with a median TSH of $99.41 \mathrm{mUI} / \mathrm{mL}$ (55.02-162.25). Thirteen patients (10.9\%) presented positive TgAb. Table 1 shows the clinical and laboratory characteristics of the studied patients.

\section{Cytological Results}

Fifty-four patients (50.4\%) presented a positive cytology, $35(32.7 \%)$ presented a negative cytology, and 18 $(16.8 \%)$ had unsatisfactory results. Twelve (10\%) patients were excluded from this analysis because of lack of cytology data. Of the patients with a negative cytology, 2 underwent surgery because of elevated FNA-Tg, and malignancy was confirmed in histology. Among the patients
Table 1. Clinical and laboratory characteristics of the 119 patients with thyroid cancer and enlarged cervical lymph nodes

\begin{tabular}{lc} 
Age, years & $45.9 \pm 16.52$ \\
Female & $89(74.8)$ \\
Histology & \\
$\quad$ Papillary & $105(92.9)$ \\
$\quad$ Follicular & $8(7.1)$ \\
TNM & \\
$\quad$ I & $63(52.9)$ \\
$\quad$ II & $13(10.9)$ \\
$\quad$ III & $18(15.1)$ \\
$\quad$ IV & $15(12.6)$ \\
Unknown & $10(8.4)$ \\
Follow-up, months & $23(13-34)$ \\
Lymph node size, cm & $1.5(1.1-2.1)$ \\
TSH, mUI/mL & \\
$\quad$ On T4 $(n=96)$ & $0.16(0.03-1.78)$ \\
Off T4 $(n=18)$ & $99.41(55.02-162.25)$ \\
Positive anti-thyroglobulin antibodies & $13(10.9)$ \\
\hline
\end{tabular}

Values are shown as mean \pm standard deviation, $n(\%)$, or median (range). ${ }^{1}$ Six patients (5\%) without histology information.

Table 2. FNA-Tg values and cytological results according to the lymph node classification

\begin{tabular}{lcc}
\hline & Benign $(n=54)$ & Metastatic $(n=65)$ \\
\hline FNA-Tg, ng/mL & $0.2(0.2-0.2)$ & $3,263.0(838.55-12,507.5)$ \\
Cytology, $n(\%)$ & & \\
Positive & $1(2.2)$ & $53(85.5)$ \\
Negative & $33(73.3)$ & $2(3.2)$ \\
Unsatisfactory & $11(24.4)$ & $7(11.3)$ \\
\hline
\end{tabular}

with an unsatisfactory cytology, 7 were submitted to surgery because of an elevated FNA-Tg and confirmed malignant histology. Table 2 shows the cytological results and correlation with FNA-Tg according to the LN classification.

\section{FNA-Tg Results}

The median FNA-Tg in benign LNs was $0.2 \mathrm{ng} / \mathrm{mL}$ $(0.2-0.2)$, while in metastatic LNs it was $3,263.0 \mathrm{ng} / \mathrm{mL}$ (838.55-12,507.5). Of the 53 patients submitted to surgery, LN DTC metastasis was confirmed in 51 (96.2\%). Two patients had elevated FNA-Tg (41.54 and 12,000.0 $\mathrm{ng} / \mathrm{mL}$ ) and no evidence of LN metastatic disease. Fourteen patients, with elevated FNA-Tg and positive cytology, were not submitted to surgery because of high surgical risk, low-volume disease, option for RAI therapy, and/ 


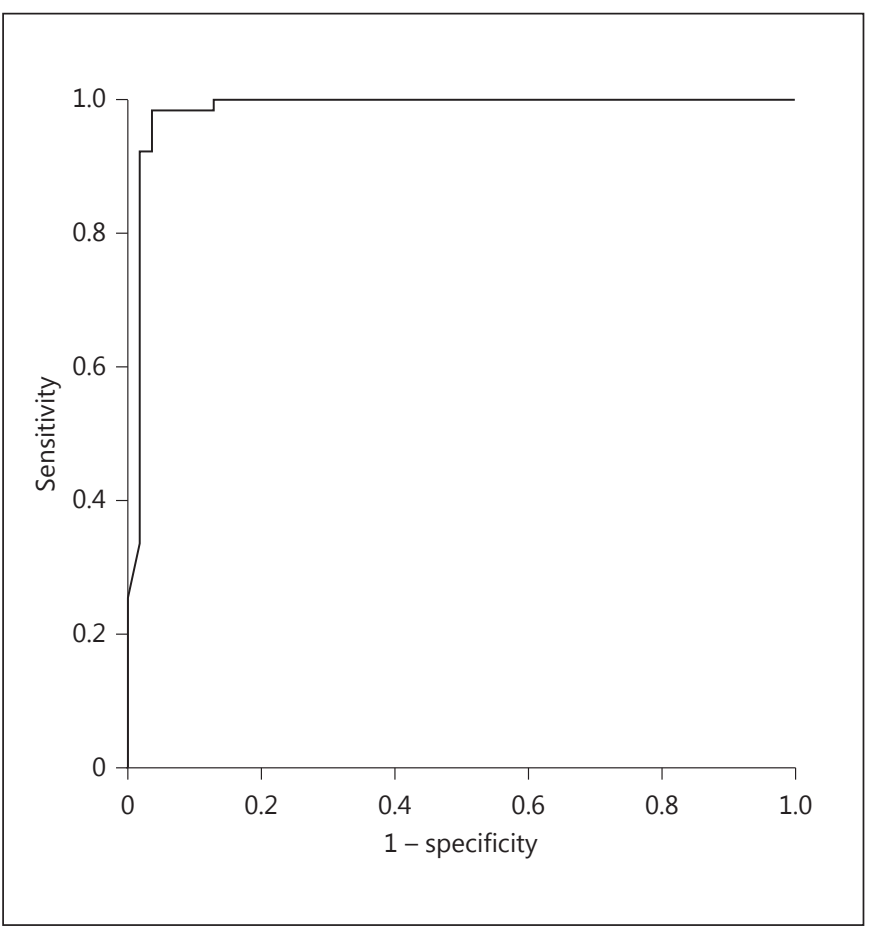

Fig. 2. ROC curve for FNA-Tg.

or clinical observation. All other patients were followed for 23 months (12-36), without clinical evidence of metastatic disease by cervical US and undetectable stimulated sTg. The values of median FNA-Tg did not differ between patients with negative $(0.2 \mathrm{ng} / \mathrm{mL})$ and those with unsatisfactory cytology $(0.29 \mathrm{ng} / \mathrm{mL} ; p=0.21)$.

\section{Serum TSH Levels and FNA-Tg Measurements}

Next, we evaluated the role of serum TSH on FNA-Tg levels. Ninety-six patients were receiving LT4 suppressive therapy and 18 patients had hypothyroidism (levothyroxine withdrawal). TSH levels were missing for 5 patients, excluded from this analysis. The median values of FNA$\mathrm{Tg}$ in patients on LT4 and off LT4 therapy were $47.94 \mathrm{ng} /$ $\mathrm{mL}(0.2-4,468)$ and $581.15 \mathrm{ng} / \mathrm{mL}(0.51-6,146.25)$, respectively. We found no significant differences in the median values of FNA-Tg between the groups $(p=0.79)$.

Of note, in all cases of positive LN disease in patients off LT4 therapy (11 patients), the FNA-Tg levels were significantly higher than sTg (at least 8-fold). The median sTg was $45.45 \mathrm{ng} / \mathrm{mL}$ (9.36-126.4) and the median FNA$\mathrm{Tg}$ was $3,577 \mathrm{ng} / \mathrm{mL}(423.58-12,000)$. In contrast, the median sTg was $3.45 \mathrm{ng} / \mathrm{mL}(0.35-25.3)$ and FNA-Tg was 0.2 $\mathrm{ng} / \mathrm{mL}(0.2-10.9)$ in patients with benign LNs. One pa- tient presented similar values of sTg and FNA-Tg (40.51 vs. $42.0 \mathrm{ng} / \mathrm{mL}$, respectively); he underwent surgery and the histologic examination was benign.

\section{Serum TgAb Levels and FNA-Tg Measurements}

Of the 119 patients, 13 had positive $\mathrm{TgAb}(10.9 \%)$ and 9 of them presented LN metastasis. Considering just patients with LN metastases (65 patients), the median FNA$\mathrm{Tg}$ did not differ between patients with positive and those with negative $\mathrm{TgAb}(88.8 \mathrm{ng} / \mathrm{mL}[4.64-13,015]$ vs. $3,263.0$ ng/mL [448.0-18,791.0], respectively; $p=0.57$ ).

\section{Cutoff Value of FNA-Tg}

Using a ROC curve to analyze the best cutoff point for FNA-Tg, the value $4.41 \mathrm{ng} / \mathrm{mL}$ obtained a sensitivity of $98 \%$ and specificity of $96 \%$, area under the curve 0,984 (95\% CI 0,958-1,0; Fig. 2). In all patients without LN disease, confirmed by negative cytology and at least 1-year follow-up, the FNA-Tg was below $4.41 \mathrm{ng} / \mathrm{mL}$ with a median of $0.2 \mathrm{ng} / \mathrm{mL}(0.2-0.2)$ (Table 2). When including only patients with positive $\operatorname{TgAb}$ (13 patients), the cutoff was $0.53 \mathrm{ng} / \mathrm{mL}$ with $100 \%$ of sensitivity and specificity.

Of interest, 4 patients were submitted to FNA-Tg dosage before thyroidectomy. Three of them had elevated FNA-Tg $(1,596.2,3,000$, and $36.2 \mathrm{ng} / \mathrm{mL})$ and underwent surgery, and LN metastases were confirmed in the anatomopathologic examination, while 1 patient had FNA-Tg $<0.2 \mathrm{ng} / \mathrm{mL}$ and did not show disease progression during follow-up. The statistical analysis was performed excluding these non-thyroidectomized patients, but the cutoff point in the ROC curve did not change.

\section{Discussion}

This study supports that measurement of FNA-Tg is an excellent tool to evaluate suspicious LNs in patients with DTC, independently of TSH status and presence of TgAb. The values of FNA-Tg did not differ between patients with positive and those with negative $\mathrm{TgAb}$ or between patients receiving and those not receiving LT4 suppressive therapy.

FNA-Tg measurement was initially suggested in 1992 by Pacini et al. [21], who showed that higher FNA-Tg in the LNs of individuals subjected to thyroidectomy and RAI ablation was due to thyroid carcinoma metastasis, whereas undetectable FNA-Tg indicated inflammatory or nonthyroidal lymphadenopathy. In 2015, Pak et al. [19] published a systematic review evaluating the best cutoff for FNA-Tg, separating preoperative and postop- 
erative values recommended for identifying neck LN metastasis: 0.9 and $32.04 \mathrm{ng} / \mathrm{mL}$, respectively. In 2013, Moon et al. [20] showed, in a large-scale validation study, that the best cutoff for FNA-Tg was 2.24 and $1.09 \mathrm{ng} / \mathrm{mL}$ for patients before and after thyroidectomy, respectively [16]. A previous study of our population identified $10 \mathrm{ng} /$ $\mathrm{mL}$ as the best cutoff value with $100 \%$ sensibility and specificity [17]. Here, we demonstrated that the cutoff $4.41 \mathrm{ng} / \mathrm{mL}$ showed elevated sensibility and specificity $(98$ and $96 \%$, respectively), improving the evaluation of suspicious LNs in these patients.

In addition, methodological challenges arise when analyzing FNA-Tg, including interassay variability, insufficient sensitivity, and presence of interfering $\mathrm{TgAb}$ in patient serum. The interference of $\mathrm{TgAb}$ in sTg is, without doubt, a technical problem that renders it difficult to use sTg as a tumor marker for DTC follow-up, but these influences in FNA-Tg dosage are still a challenge. Baskin [22] first suggested that positive $\mathrm{TgAb}$ in the serum did not affect FNA-Tg, possibly because the intracellular Tg is not exposed to circulating TgAb. Boi et al. [23] agree that FNA-Tg is an excellent method even in the presence of $\mathrm{TgAb}$, justifying that the exceedingly elevated $\mathrm{Tg}$ concentration in positive FNA-Tg is able to saturate $\mathrm{TgAb}$ binding sites. Sigstad et al. [24] also showed that TgAb appears to have a negligible effect on the clinical performance of FNA-Tg. On the other hand, in 2013, Jeon et al. [25] reported that patients with positive $\mathrm{TgAb}$ may present a falsely negative FNA-Tg. Nevertheless, the same group found no relationship between $\mathrm{TgAb}$ and FNA-Tg in later studies [19].

In agreement with previous studies, we showed that the serum TSH and TgAb do not seem to interfere in the detectable FNA-Tg levels. Of note, however, there was a patient with positive $\mathrm{TgAb}(84.2 \mathrm{IU} / \mathrm{mL})$, negative FNA$\mathrm{Tg}(0.71 \mathrm{ng} / \mathrm{mL})$, and malignant cytology who was submitted to surgery and in whom malignant LNs were confirmed. Thus, a possible limitation of this conclusion is that there were few positive $\mathrm{TgAb}$ patients and 5 patients (4.2\%) who were not submitted to TgAb dosage and were not included in this specific analysis.

Our study has some limitations. None of the 32 patients with a benign cytology and negative FNA-Tg underwent LN surgery. In these patients, we cannot provide evidence of benign histology. Consequently, false negatives in cytology associated with negative FNA-Tg cannot be excluded. To overcome this limitation, we have used stimulated sTg measurement after a 1year follow-up considering sTg values $<1 \mathrm{ng} / \mathrm{mL}$ as an indication that the patient was disease-free.

In conclusion, our results showed that US-guided FNA-Tg should be performed as an adjunct to cytology in patients with suspicious cervical LNs. In our population, the cutoff of $4.41 \mathrm{ng} / \mathrm{mL}$ showed elevated sensibility and specificity of 98 and $96 \%$, respectively. Therefore, this method proved to be a useful examination in the followup of patients with DTC, independently of TSH status and presence of $\mathrm{TgAb}$, and can contribute to diminish the number of unnecessary surgeries, reducing costs and patient morbidity.

\section{Disclosure Statement}

M.A.S.D, A.B.Z, A.P.C., C.S.F., M.S.G., and A.L.M. have nothing to declare.

\section{References}

1 http://seer.cancer.gov/statfacts/html/thyro. html.

2 Sierra MS, Soerjomataram I, Forman D: Thyroid cancer burden in Central and South America. Cancer Epidemiol 2016;44(suppl 1): S150-S157.

3 Enewold L, Zhu K, Ron E, Marrogi AJ, Stojadinovic A, Peoples GE: Rising thyroid cancer incidence in the United States by demographic and tumor characteristics, 1980-2005. Cancer Epidemiol Biomarkers Prev 2009;18:784.

4 Chen AY, Jemal A, Ward EM: Increasing incidence of differentiated thyroid cancer in the United States, 1988-2005. Cancer 2009;115: 3801.
5 Scheffel RS, Zanella AB, Antunes D, Dora JM, Maia AL: Low recurrence rates in a cohort of differentiated thyroid carcinoma patients: a referral center experience. Thyroid 2015;25: 883-889.

6 Grant CS, Hay ID, Gough IR, et al: Local recurrence in papillary thyroid carcinoma: is extent of surgical resection important? Surgery1988;104:954-962.

7 Cignareli M, Ambrosi A, Marino A, Lamacchia O, Campo M, Picca G, et al: Diagnostic utility of thyroglobulin detection in fine-needle aspiration of cervical cystic metastatic lymph nodes from papillary thyroid cancer with negative cytology. Thyroid 2003;13: 1163-1167.
8 Leboulleux S, Girard E, Rose M, Travagli JP, Sabbah N, Caillou B, Hartl DM, Lassau N, Baudin E, Schlumberger M: Ultrasound criteria of malignancy for cervical lymph nodes in patients followed up for differentiated thyroid cancer. J Clin Endocrinol Metab 2007;92: 3590-3594.

-9 Leonard N, Melcher DH: To operate or not operate? The value of fine needle aspiration cytology in the assessment of thyroid swellings. J Clin Pathol 1997;50:941-943.

10 Cáp J, Ryska A, Rehorková P, Hovorková E, Kerekes Z, Pohnetalová D: Sensitivity and specificity of the fine needle aspiration biopsy of the thyroid: clinical point of view. Clin Endocrinol (Oxf) 1999;51:509-515. 
11 Boland GW, Lee MJ, Mueller PR, Mayo Smith W, Dawson SL, Simeone JF: Efficacy of sonographically guided biopsy of thyroid masses and cervical lymph nodes. Am J Roentgenol 1993;161:1053-1056.

12 Takashima S, Shusuke S, Nomura N, Tomiyama N, Kobayshi T, Nakamura H: Nonpalpable lymph nodes of the neck: assessment with US and US-guided fine-needle aspiration biopsy. J Clin Ultrasound 1997;25:283292.

13 Costante G, Filetti S: Thyroglobulin in fineneedle aspirate: a clue to metastasis? Nat Rev Endocrinol 2009;5:249-250.

14 Chung J, Kim EK, Lim H, Son EJ, Yoon JH, Youk JH, Kim JA, Moon HJ, Kwak JY: Optimal indication of thyroglobulin measurement in fine-needle aspiration for detecting lateral metastatic lymph nodes in patients with papillary thyroid carcinoma. Head Neck 2014;36: 795-801

-15 Torres MRS, Nóbrega Neto SH, Rosas RJ, Martins ALB,4 Ramos ALC, Cruz TRP: Thyroglobulin in the washout fluid of lymphnode biopsy: what is its role in the follow-up of differentiated thyroid carcinoma? Thyroid 2014;24:7-18.

16 Jeon MJ, Kim WG, Jang EK, Choi YM, Lee Y-M, Sung T-Y, Yoon JH, Chung K-W, Hong SJ, Baek JH, Lee JH, Kim TY, Shong YK, Kim WB: Thyroglobulin level in fine-needle aspirates for preoperative diagnosis of cervical lymph node metastasis in patients with papillary thyroid carcinoma: two different cutoff values according to serum thyroglobulin level. Thyroid 2015;25:410-416.
17 Zanella AB, Souza Meyer EL, Balzan L, Silva AC, Camargo J, Migliavacca A, Guimaraes JR, Maia AL: Thyroglobulin measurements in washouts of fine needle aspirates in cervical lymph nodes for detection of papillary thyroid cancer metastases. Arq Bras Endocrinol Metabol 2010;54:550-554.

18 Jo K, Kim MH, Lim Y, Jung SL, Bae JS, Jung CK, Kang MI, Cha BY, Lim DJ: Lowered cutoff of lymph node fine-needle aspiration thyroglobulin in thyroid cancer patients with serum anti-thyroglobulin antibody. Eur J Endocrinol 2015;173:489-497.

19 Pak K, Suh S, Hong H, Cheon GJ, Hahn SK, Kang KW, Kim EE, Lee DS, Chung JK: Diagnostic values of thyroglobulin measurement in fine-needle aspiration of lymph nodes in patients with thyroid cancer. Endocrine 2015; 49:70-77.

20 Moon JH, Kim YI, Lim JA, Choi HS, Cho SW, Kim KW, Park HJ, Paeng JC, Park YJ, Yi KH, Park DJ, Kim SE, Chung JK: Thyroglobulin in washout fluid from lymph node fine-needle aspiration biopsy in papillary thyroid cancer: large-scale validation of the cutoff value to determine malignancy and evaluation of discrepant results. J Clin Endocrinol Metab 2013;98:1061-1068.
21 Pacini F, Fugazzola L, Lippi F, Ceccarelli C, Centoni R, Miccoli P, Elisei R, Pinchera A: Detection of thyroglobulin in fine-needle aspirates of nonthyroidal neck masses: a clue to the diagnosis of metastatic differentiated thyroid cancer. J Clin Endocrinol Metab 1992;74: 1401-1404.

22 Baskin HJ: Detection of recurrent papillary thyroid carcinoma by thyroglobulin assessment in the needle washout after fine-needle aspiration of suspicious lymph nodes. Thyroid 2004;14:959-963.

23 Boi F, Baghino G, Atzeni F, Lai ML, Faa G, Mariotti S: The diagnostic value for differentiated thyroid carcinoma metastases of thyroglobulin $(\mathrm{Tg})$ measurement in washout fluid from fine-needle aspiration biopsy of neck lymph nodes is maintained in the presence of circulating anti-Tg antibodies. J Clin Endocrinol Metab 2006;91:1364-1369.

24 Sigstad E, Heilo A, Paus E, Holgersen K, Grøholt KK, Jørgensen LH, Bogsrud TV, Berner A, Bjøro T: The usefulness of detecting thyroglobulin in fine-needle aspirates from patients with neck lesions using a sensitive thyroglobulin assay. Diagn Cytopathol 2007; 35:761-767.

25 Jeon MJ, Park JW, Han JM, Yim JH, Song DE, Gong G, Kim TY, Baek JH, Lee JH, Shong YK, Kim WB: Serum antithyroglobulin antibodies interfere with thyroglobulin detection in fineneedle aspirates of metastatic neck nodes in papillary thyroid carcinoma. J Clin Endocrinol Metab 2013;98:153-160. 